\title{
Boutique Hotel in Badung-Bali District Application of Luxurious Concepts in Exclusive Type Room Interiors
}

\author{
Bachelor Degree of Architecture Study Program \\ Faculty of Engineering-Udayana University \\ Jimbaran \\ savitripratishita@gmail.com \\ Architecture Study Program \\ Faculty of Engineering-Udayana University \\ Jimbaran \\ Architecture Study Program \\ Faculty of Engineering-Udayana University \\ Jimbaran
}

Komang Savitri Pratishita Santhi ${ }^{1}$, Ni Ketut Ayu Siwalatri ${ }^{2}$, I Wayan Wiryawan ${ }^{3}$

\begin{abstract}
As the time passes by, people's lifestyles and tourism in Bali have developed rapidly. Business people have made ho-tels the main target in tourism because it means to providing services includes hotel, hostel or motel. Therefore this fa-cility is very important for developed of tourism in Bali. The ambience and concepts that are owned by the hotels, espe-cially in the rooms, are very influential to increase the number of tourists who wish to stay at the hotels, both from the in-terior design and atmosphere that is served and able to make tourists feel comfortable. Luxurious hotel is one of the hotels that has been loved by many people today and has developed throughout the hospitality industries, especially 5 stars standard hotels. Interior design with luxury concept has characteristics that can be seen from using materials of good quality and aesthetic value which are more than the value of its function. The application of this luxurious concept in the interior of hotel rooms such as several parts in the form of upper elements that use ceiling and hanging lamps and walls that use wooden partitions arranged vertically and use of materials with gold and neutral colors such as brown and white on most interior elements in the boutique hotel room. With the application of the luxurious concept, can create the ambience of the space become more elegant.
\end{abstract}

Index Terms - luxury,boutique,hotel,interior.

\section{INTRODUCTION}

Hotels are commercially managed accommodation facilities, provided for everyone to obtain services in the form of lodging, food and drinks. Based on the luxury level of the hotel, boutique hotels are five-star hotels with a number of room units that are classified as small but have luxury room types that are equipped with luxury facilities both in terms of the completeness of the hotel and in terms of its architecture. The hotel is located in an urban area close to the beach to maximize views, because the placement of the view is a high selling point so it can attract tourists to visit. The main components of this boutique hotel are exclusive foreign tourists who prioritize extra comfort during travel and stays, therefore boutique hotels are here to complement their needs, one of which is providing room facilities by applying the luxurious concept so as to make tourists comfortable doing activity in the room. Besides determining the location of the hotel also affects the feasibility of a 5-star hotel so that it has good prospects for the future. Among the regencies in Bali, Badung Regency is one of the regencies designated as a national strategic area in the field of tourism in Bali. One of the main targets of tourists in this Badung regency is the tourist attraction in the form of the beach which makes it an added value for 
boutique hotels to determine the placement of views for every facility in the hotel, especially in hotel rooms.

\section{RESUlt AND ANALISYS}

\section{A. Luxurious Concept}

Basically, a hotel provides various facilities and services for the comfort, safety, and satisfaction of tourists who stay, while the main facilities of a hotel are bedrooms. The bedroom is a place where tourists come to rest. As a commercial facility, comfort is an important aspect that is closely related to the high and low number of tourist visits at the hotel. One of the realization of comfort in a hotel building can be classified based on the facilities provided and the arrangement of space in each room. Lack of design space in the room can reduce the comfort of the civitas at the hotel. Kenya tourists in a hotel room can be measured by the size of a room. The standard area and hotel facilities of a 5 star standard are as follows, (1) bedrooms including bathrooms, (2) all suites, (3) doors are equipped with safety locks, (4) good lighting and circulation, (5) minimum area of $50 \mathrm{~m} 2$, (6) all complete facilities (TV, Wi-Fi, king size bed, bedside table, mirror, reading lam, safe deposit box)

Determination of the concept of rooms in a hotel can also have a major effect on the comfort and harmony of buildings with one another, the concept applied to boutique hotels, especially in in-terior rooms is luxury, this concept is only applied to residential and luxurious rooms and focuses on the use of furniture and good quality material and has aesthetic value more than the value of its function. The application of luxurious concepts in room interiors includes aspects of the use of furniture, aesthetic elements, walls, floors, colors and lighting. The characteristics of the luxurious concept are as follows, (1) the use of furnishing with materials with special workmanship, (2) has an aesthetic value that is more than the value of its function, (3) uses furniture and interior elements of good quality and seems luxurious and is specially designed by the famous desaigner. (4) the use of precious metal materials such as gold and silver. (5) the interior elements used prioritize art rather than functional purposes.

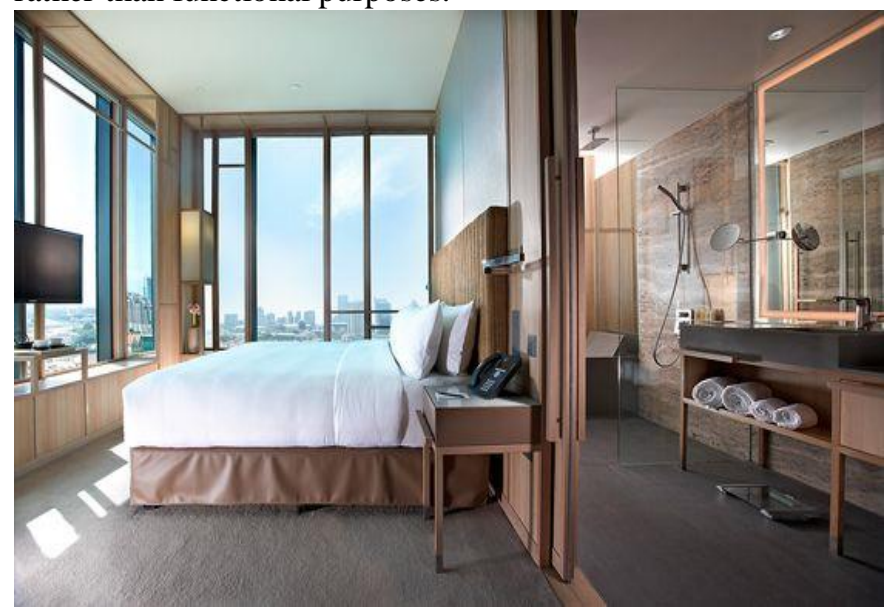

Fig. 1. Luxury Model Interior (source: Shanti:2017)
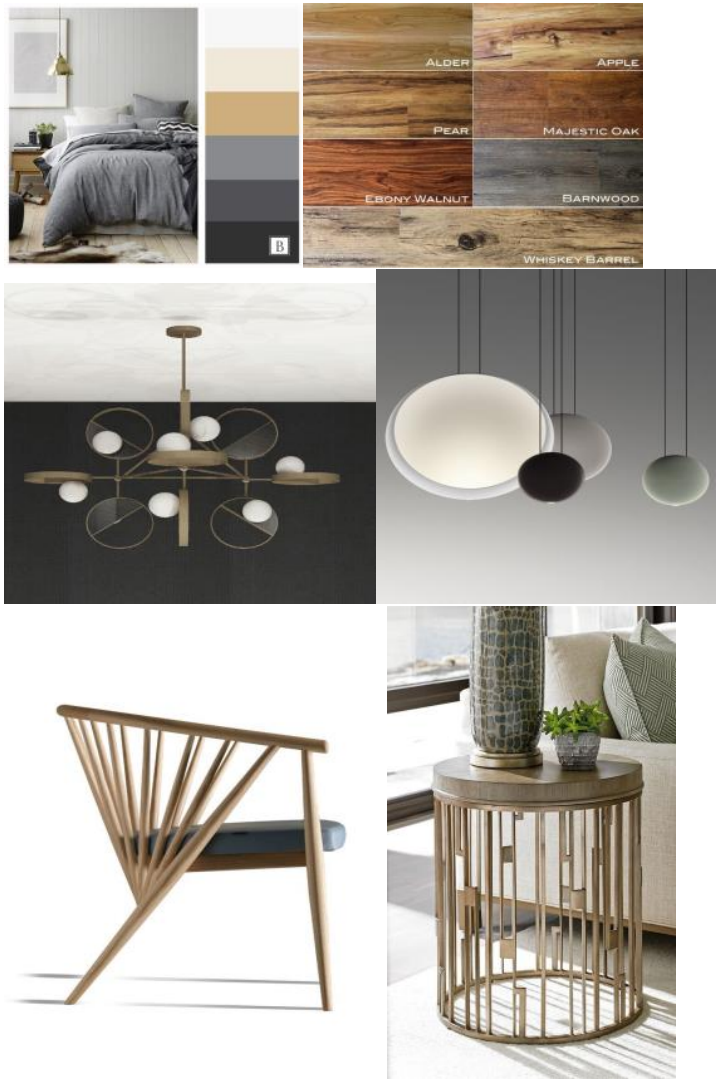

Fig. 2. Luxury Furniture Interior (source: Shanti:2017)

\section{B. Application of the Luxurious Concept in the Exclusive Type Interior}

The level of comfort of a person is strongly influenced by the physical environment which consists of the condition of the building and the condition of the interior. Therefore the arrangement of space in being an important aspect and special attention in determining the concept of the space within itself. The elements of space in an exclusive type hotel room consist of elements above, below and side (ceiling, floor, wall) which aims to protect the safety and comfort of the civitas in the room. Based on the criteria of the luxuri-ous concept, the application of the concept of luxury in the interior of an exclusive type room can be applied to the elements of space as follows. The upper element (ceiling) in the exclusive room type only uses a ceiling made of wood material with the addition of chandeliers with a unique shape but simple but elegant.

The application of side elements using white paint finishing combined with the application of a tubular divider arranged vertically to give the impression of a room breaker without having to close all views in the other direction. To make a broad impression on the divider section in the form of a pipe can be combined using glass. As for the lower element, the floor duplication in the interior of this room uses a parquet to add the impression of luxury and luxury. 


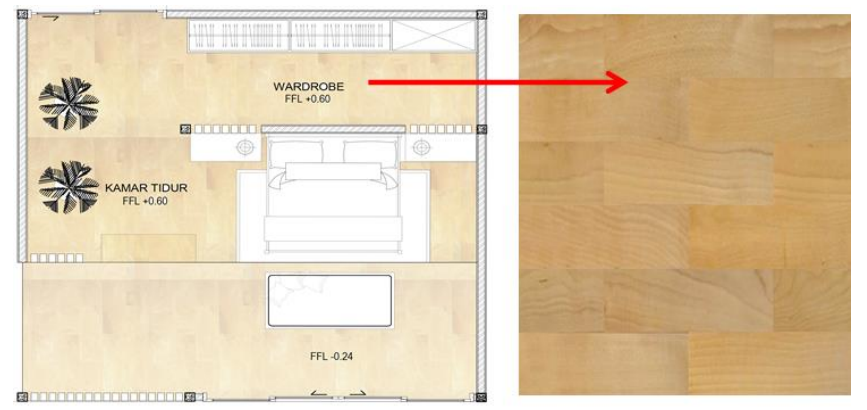

Fig. 3. Floor Material

The application of the parquet in the el-emen under the hotel room aims to give the impression of luxury and elegance so that guests are comfortable in that room.

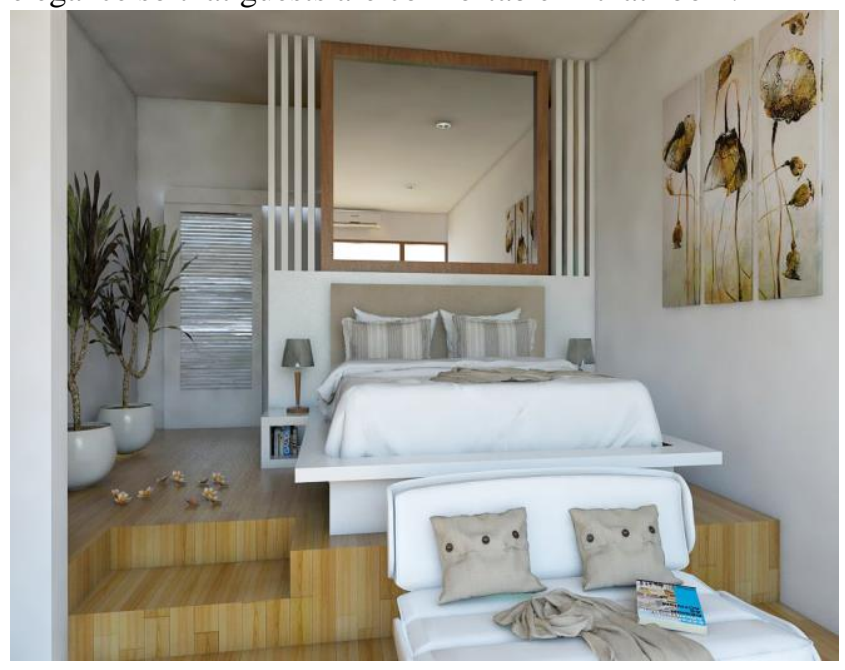

Fig. 4. Perspective Interior (source: Shanti:2017)

The application of furniture in the interior of the room uses geometric and arched furniture with a wide angle and uses a neutral color combination with a wooden frame that has a small diameter. As for the application of color finishing in this interior using natural colors such as wood color that is brown combined with other neutral colors such as white, gray and golden brown. Lighting in this room uses indirect lighting such as hidden lights that are located above the ceiling or on the floor.

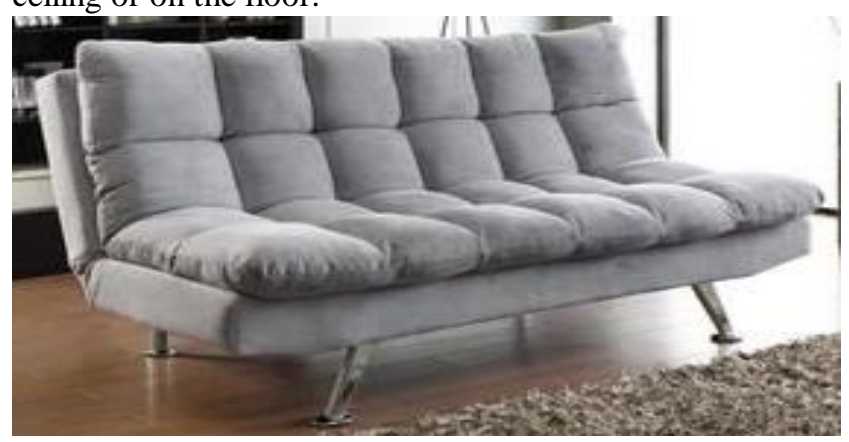

Fig. 5. Furniture for Interior (source: Shanti:2017)

\section{Interior Design}

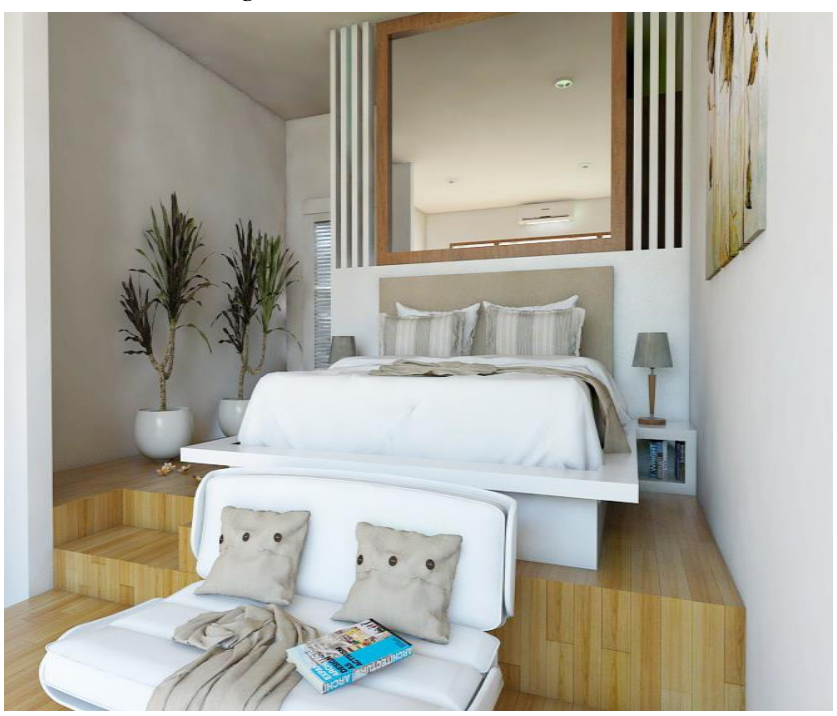

Fig. 6. Interior Concept

Application of furniture using geometric shapes and using a neutral color combination can make the atmosphere of the room to be more elegant.

\section{CONCLUSION}

By using the luxurious concept in this exclusive room type, it can increase the interest of foreign tourists to come and stay at boutique hotels because most of the foreign tourists tend to like the exclusive atmosphere. The application of this luxurious concept can be applied using artwork and chandeliers on the ceiling, using panels made of wood and dividers made of metal on the walls, using parquet on the bottom element, using simple and geometric shapes for furniture, using neutral colors, and using indirect lighting with warm colors. So that the appropriate arrangement of space in the room will make the civitas space users become more comfortable when in the room.

\section{REFERENCES}

[1] Rutes, W., \& Penner, R., "Hotel Planning and Design", New York : Watson-Guptill Publications, 1985. 